УДК 656.039.7:[663.4+663.97] (476)

https://doi.org/10.47612/978-985-7149-55-1-2020-238-241

Лада Язубец, старший преподаватель

Гродненский государственный аграрный университет, г. Гродно

\title{
Акциз как инструмент государственного \\ регулирования рынка отдельных товаров в Республике Беларусь \\ (на примере пивоваренной и табачной продукции)
}

С учетом экономической ситуации каждое государство может вводить акцизы на те или иные товары в зависимости от его интересов. Акцизы используются более чем в 40 странах мира, в том числе в 17 европейских государствах - членах Европейского союза. Ставки этого налога в последние годы имеют выраженную тенденцию к сближению в целях создания одинаковых конкурентных условий на общем рынке ЕС. Как правило, они взимаются в дополнение к НДС, которым облагаются соответствующие товары или услуги [2, 7, 9].

На размер косвенных налогов влияет, прежде всего, уровень экономического развития страны. Чем ниже этот уровень, тем большую долю в общем объеме налогов составляют косвенные налоги. И наоборот, чем выше уровень экономического развития страны, тем больше доля прямых налогов. Подобная количественная закономерность обусловлена тем, что в слаборазвитых странах население не может платить прямые налоги $[1,2]$.

Гармонизация национальных систем налогообложения в ЕС преследует следующие цели:

$>$ обеспечить нейтральность налогов с точки зрения условий конкуренции на едином рынке, иными словами, установить недискриминационный налоговый режим для всех его участников;

$>$ создать условия для отмены контроля на внутренних границах ЕC;

$>$ устранить возможность двойного налогообложения прибылей компаний, осуществляющих деятельность в двух или более странах ЕС;

$>$ исключить возможность уклонения от уплаты налогов и гарантировать поступление соответствующих доходов в бюджеты стран-членов.

Гармонизация акцизов, несмотря на их относительную простоту и сходство в методах взимания, связана с рядом специфических трудностей. Во-первых, акцизами в основном облагаются товары широкого потребления, и их гармонизация затрагивает интересы практически всех слоев населения. Во-вторых, сближение акцизов приходится увязывать с правилами единой политики в области сельского хозяйства (например, табак). Нельзя не учитывать также различия в действующих стандартах, требованиях по защите интересов потребителей, национальных традициях и вкусах [7].

Одна из ключевых задач политики Республики Беларусь в области налогов состоит в наращивании налоговых поступлений в бюджет. Для достижения поставленной цели предстоит резко повысить аккумулирование налогов, то есть соотношение фактических поступлений налогов и налогового потенциала, под которым понимается максимально возможная в данный момент их величина.

Повышение аккумулирования налогов является одной из важнейших задач налоговой и всей экономической политики. Органы законодательной и исполнительной власти в последние годы уделяют ее решению значительное внимание, однако, по мнению многих экономистов, добиться ожидаемых результатов пока не удается. Для этого необходимо существенно улучшить технику и технологию налогообложения, включающую методы налогового администрирования, устранить недостатки правовой базы налогового регулирования, а главное - сделать уклонение от уплаты налогов экономически невыгодным для граждан и предприятий [3].

Поступления налогов в бюджет определяются с учетом коэффициента аккумулирования и показателя, обозначенного как «реально возможная сумма поступлений», поскольку известно, что налоги поступят в казну не в полном объеме. Относительно низкий коэффициент собираемости закладывается в расчетах по тем видам продукции, по которым не существует достаточно полного учета производства и реализации. Таким образом, в самих расчетах доходной части бюджета закладывается частичное неисполнение налоговых обязательств хозяйствующих субъектов.

Поступления в бюджет доходов от акцизов дифференцированы по товарам и разделены на внутренние (акцизы от производства продукции) и внешние (акцизы, взимаемые с импортируемой продукции) источники поступления $[8,10]$. Увеличение поступлений акцизов от внутреннего производства пивоваренной и табачной продукции обусловлено относительным ростом производства, который стал возможным благодаря усилению государственного контроля за производством и оборотом пивоваренной и табачной продукции, ужесточению административных мер по сбору акцизов, а также за счет внесения корректировок в налоговое законодательство по акцизам (в сторону повышения их ставок).

В качестве основных причин снижения поступлений акцизов от импорта подакцизной продукции в бюджет можно назвать переориентацию хозяйствующих субъектов с импортных операций на производство товаров внутри страны и высокий уровень налогообложения подакцизных товаров при их ввозе на территорию республики. Примером может служить организация 
производства сигарет иностранных марок, расширение перечня и номенклатуры выпускаемого пива [5, 15].

Депрессивное воздействие акциза на производство и потребление пивоваренной и табачной продукции может быть оправдано стремлением ослабить негативное влияние этого специфического продукта на здоровье общества [16].

На первый взгляд, при установлении акцизов государство вынуждено преследовать фискальные цели. Так, потребитель в последние годы среди алкогольной продукции отдает предпочтение слабоалкогольным напиткам.

Посредством акцизов в государственный бюджет изымается часть цены товара как денежного выражения его стоимости, которая обусловлена не экономическим эффектом его создания или потребительскими свойствами, а особыми условиями его производства и продажи. Если бы эта часть цены не изымалась в бюджет, то предприятие-изготовитель данной продукции получало бы незаслуженно высокую прибыль и было бы поставлено в неравные, предпочтительные по сравнению с другими предприятиями, условия [1].

Если для конечных плательщиков акцизов - для потребителей обложенного налогом товара - косвенные налоги могут показаться менее обременительными, то производители могут не только сильно пострадать, но и разориться вследствие введения нового акциза, увеличения его размера или изменения формы взимания. Акцизы, уплачиваемые производителями прежде, чем произведенный ими товар перейдет в руки потребителей, вызывают необходимость в большом оборотном капитале, что увеличивает издержки производства и повышает цену продукта. Введение налога вынуждает производителя минимизировать прибыль за счет увеличения издержек производства (например, включение в цену стоимости возвратной тары, упаковки, складских расходов и т. д.).

Акциз, являясь ценообразующим налогом, направлен только на повышение цены, однако цену товара можно увеличивать за счет косвенного налога до известных пределов. Этот предел определяется на рынке. При соответствующем учете влияния основных факторов на рыночную конъюнктуру и их отсечении можно установить ее зависимость от налоговых ставок.

В целом, при кажущейся простоте вопроса об установлении акцизов на пивоваренную и табачную продукцию, их взимание связано с возникновением комплекса весьма непростых проблем (и для государства, и для плательщиков): установление возможных границ реальных ставок; применение видов ставок (адвалорных и специфических); периодичность взимания и привязка акцизов к стадии воспроизводственного процесса (к производству сырья или конечной продукции, импорту, оптовой или розничной продаже) и др.

Качественной характеристикой налоговой системы является тяжесть налогообложения, однако до сих пор отсутствует общепринятая методика ее исчисления. Существуют лишь разрозненные показатели, которые в косвенной форме могут давать представление о тяжести налогообложения $[4,11,12]$.
Акцизы способствуют изъятию доходов, которые включены в цену товара. Подакцизные товары облагаются НДС с учетом акциза, что приводит к двойному налогообложению этих товаров: налогом облагается величина другого налога, то есть сумма акциза включается в базу обложения налогом на добавленную стоимость. Акциз, включаемый в цену сырья и материалов увеличивает себестоимость производимых товаров, удорожает их. Установление специфической ставки акциза позволяет производителю не только улучшать качество продукции, но и увеличивать расходы на ее оформление. В случае установления специфической ставки акциза на продукцию увеличение выручки от ее реализации на основе повышения ее качества или цены не высвободится полностью в доход государства и, следовательно, не спровоцирует такие негативные явления, как уклонение от налогообложения, применение наличных расчетов, спад инвестиций и производства, контрабандный ввоз.

Определенный интерес представляет разработка ученых-экономистов, которые предлагают использовать для оценки тяжести налогового бремени показатели приростной полной ставки налогообложения добавленной стоимости, связанной с фондом оплаты труда. Данный показатель рассчитывается как отношение прироста всех налоговых (обязательных) платежей к вызвавшему его увеличению отпускной цены (цены потребителя) при заданных налоговых ставках. Показатель полной приростной ставки налогообложения может рассматриваться и как максимально возможная доля чистого дохода работника в приросте выручки от реализации продукции, полученного вследствие повышения эффективности производства $[12,15,17]$.

Акцизы и другие налоги на выручку от реализации не могут быть полностью учтены при расчете приростных ставок, поскольку начисляются не на добавленную стоимость, а на всю стоимость товара. Тем не менее данный подход представляет большой интерес, поскольку наряду с валовыми показателями общепризнанными инструментами анализа экономического поведения и хозяйственной деятельности рыночных субъектов стали приростные величины.

Акциз на пивоваренную продукцию по адвалорным ставкам в равной мере депрессивно влияет на изменение выручки как вследствие роста производства и потребления, так и в результате роста цены из-за повышения издержек и улучшения качества продукции. Другими словами, капиталовложения как в наращивание производства пивоваренной продукции, так и в повышение качества продукции одинаково подавляются акцизами, что экономически не оправдано. Выбор в качестве налоговой базы выручки от реализации ведет к высокой зависимости производства и продаж от себестоимости. Это и обусловило возврат к установлению специфических ставок акцизов на единицу. При применении специфических ставок акциза на пивоваренные напитки резко упрощается взимание акцизов, контроль за производством и продажей продукции.

Действие (влияние) акциза имеет некоторую двойственность. С одной стороны, акциз предназначен для 
сдерживания роста нормы прибыли, а с другой - при этом налоге потери должны компенсировать покупатели. Покупатель, во-первых, имеет денежные средства для потребления данных товаров, во-вторых, оплачивает этот налог $[6,13,14]$.

Изымая посредством налогов часть конечного финансового результата деятельности предприятий, государство определяет тем самым величину их инвестируемой прибыли. Уменьшение прибыли за счет эффективности предприятия в достижении цели снижает привлекательность организаций для инвесторов. При отсутствии прибыли суммарный капитал приближается к нулю, что эквивалентно оттоку инвестиций. В данном случае корректнее исследовать связь между нормой прибыли и потоком инвестиций. Если норма прибыли падает ниже банковского процента на депозит, то инвесторам выгоднее вложить деньги в банк. Закономерно возникает один из сложных вопросов в области перераспределения денежной формы стоимости - вопрос оптимизации величины налогового изъятия. Его решение зависит от понимания категории «налоговый потенциал» $[9,11,17]$.

Акциз может оказывать стимулирующее влияние на производство. Налоги в качестве инструмента государственного регулирования могут стимулировать экономию производственных ресурсов в процессе хозяйственной деятельности предприятия. В целях повышения эффективности производства обоснуем стимулирующее влияние косвенного налогообложения. Тяжесть налога на производителя может быть уменьшена, когда акциз взимается у производителя по количеству поступившего в переработку сырья или по заранее установленным признакам технико-производственного характера. При существовании акциза производитель стремится к тому, чтобы из того же количества сырья или при том же оборудовании получить большее количество продуктов, так как благодаря такому росту выработки уменьшается налог, приходящийся на единицу продукции. Этот рост производства объясняется заинтересованностью в нем производителей, уплачивавших акциз по количеству переработанного сырья.

Учет стимулирующей производство функции при усилении косвенного налогообложения возможен по двум направлениям. Во-первых, само введение новых или увеличение и изменение старых косвенных налогов должно проводиться с учетом возможности отрицательного воздействия указанных изменений на производителя. При обнаружении подобного отрицательного эффекта необходимо разрабатывать меры, способные элиминировать или хотя бы минимизировать этот эффект (вплоть до снижения акцизов), чье отрицательное влияние на производителя проявляется и прямо через процесс переложения налогов в условиях кризиса и опосредованно - через снижение потребления. Во-вторых, необходимо учитывать позитивный опыт некоторых стран с рыночной экономикой, также прибегавших на определенном этапе к усилению роли косвенных налогов. Увеличение роли косвенных налогов может оказать серьезное и долговременное положительное влияние лишь в том случае, когда полученные в результате этих мер дополнительные финансовые средства используются для проведения в рамках активной промышленной политики серьезных налоговых мер, стимулирующих экономический рост [7].

В целом высокое косвенное обложение налоговой системы выступает фактором сдерживания спроса. Косвенные налоги не связаны непосредственно с эффективностью труда и капитала. Поэтому постепенное ограничение доли косвенных налогов (акцизы и НДС) в бюджете и, соответственно, в денежных выплатах предприятий и потребителей должно отвечать целям антикризисной политики и продолжения налоговой и экономической реформ. Внедрение этого принципа в налоговую систему и в налоговое законодательство особенно важно, поскольку основная масса платежей в бюджет изымается без учета каких-либо объективных условий производства.

\section{Список использованных источников}

1. Богомолов, В. В. Акцизы на алкогольную продукцию как инструмент государственного регулирования рынка и инструмент профилактики алкоголизма среди населения России / В. В. Богомолов // Молодой ученый. - 2020. - № 21 (311). - С. 261-265.

2. Данкевич, В. Е. Влияние либерализации мировой торговли на развитие отечественных компаний пивоваренной отрасли / В. Е. Данкевич, П. В. Пивовар, Е. М. Данкевич // Проблемы экономики (Харьков). 2020. - № 1 (43). - С. 59-67.

3. Евневич, М. А. Администрирование акцизов на табачную и алкогольную продукцию / М. А. Евневич, Д. В. Иванова // Экон. науки. - 2020. - № 183. - С. 32-37.

4. Зайнуллина, 3. Ф. Уголовно-правовое противодействие контрабанде наличных денежных средств, денежных инструментов, алкогольной продукции и табачных изделий : автореф. дис. .... канд. юрид. наук : 12.00.08 / 3. Ф. Зайнуллина ; Рос. ун-т дружбы народов. - М., 2018. - 23 с.

5. Идрисов, А. А. Налоговая политика в области акцизов на табачную продукцию в России / А. А. Идрисов // Экономика и управление: проблемы, решения. 2020. - Т. 3, № 3. - С. 36-40.

6. Каллаш, В. В. Три века: Россия от смуты до нашего времени : ист. сб. : в 6 т. / В. В. Каллаш. - М. : Тов-во И. Д. Сытина. - Т. 4. - 209 с.

7. Кийко, Д. Пути гармонизации налоговых систем / Д. Кийко // Финансы. Учет. Аудит. - 2013. - № 6. С. 28-32.

8. Кисель, И. Инновационные технологии управления налогами на предприятии / И. Кисель // Аграр. экономика. - 2012. - № 10. - С. 25-29.

9. Ковтуненко, А. Н. Эволюция взглядов на роль государства в экономике / А. Н. Ковтуненко // Белорус. экон. журн. - 2013. - № 1. - С. 74-87.

10. Недоступ, А. Налоговые вычеты по акцизам в 2010 году: понятие новое - порядок старый (Комментарий к отдельным нормам гл. 13 Особенной части Налогового кодекса Республики Беларусь ) / А. Недоступ // Главный бухгалтер. - 2010. - № 6. - С. 22-27. 
11. О внесении дополнений в Кодекс Республики Беларусь об административных правонарушениях и Процессуально-исполнительный кодекс Республики Беларусь об административных правонарушениях : Закон Респ. Беларусь, 25 нояб. 2011 г., № 317-3 // Нац. реестр правовых актов Респ. Беларусь. - 2011. - № 134. $2 / 1869$.

12. Панфилова, Н. Е. Уголовно-правовое и криминологическое противодействие контрабанде денежных средств и (или) денежных инструментов, алкогольной продукции и (или) табачных изделий : автореф. дис. ... канд. юрид. наук : 12.00 .08 / Н. Е. Панфилова ; Казан. (Приволж.) федер. ун-т. - Казань, 2018. $28 \mathrm{c}$.

13. Петти, У. Трактат о налогах / У. Петти // Антология экономической классики : в 2 т. - М., 1993. - Т. 1. C. $78-79$.
14. Рикардо, Д. Начало политической экономии и подакцизного обложения / Д. Рикардо. - М. : Эксмо, 2009. $-953 \mathrm{c}$.

15. Сайганов, А. Научные предпосылки формирования и эффективного функционирования рынка пивоваренной продукции с учетом осведомленности потребителей о брэндах пива / А. Сайганов, В. Стрелкова // Аграр. экономика. - 2020. - № 3 (298). - С. 52-63.

16. Сайганов, А. С. Оценка потенциала устойчивого развития мирового рынка пивоваренной продукции / А. С. Сайганов, В. Г. Стрелкова // Сб. науч. тр. «Проблемы экономики». - 2019. - Вып. 2 (29). - С. 223-234.

17. Саломатин, В. А. Оценка формирования потребительской цены на табачную продукцию / В. А. Саломатин, Е. В. Саломатина, С. В. Калашников // Экономика, предпринимательство и право. -2020 . - Т. 10, № 5. C. $153-162$.

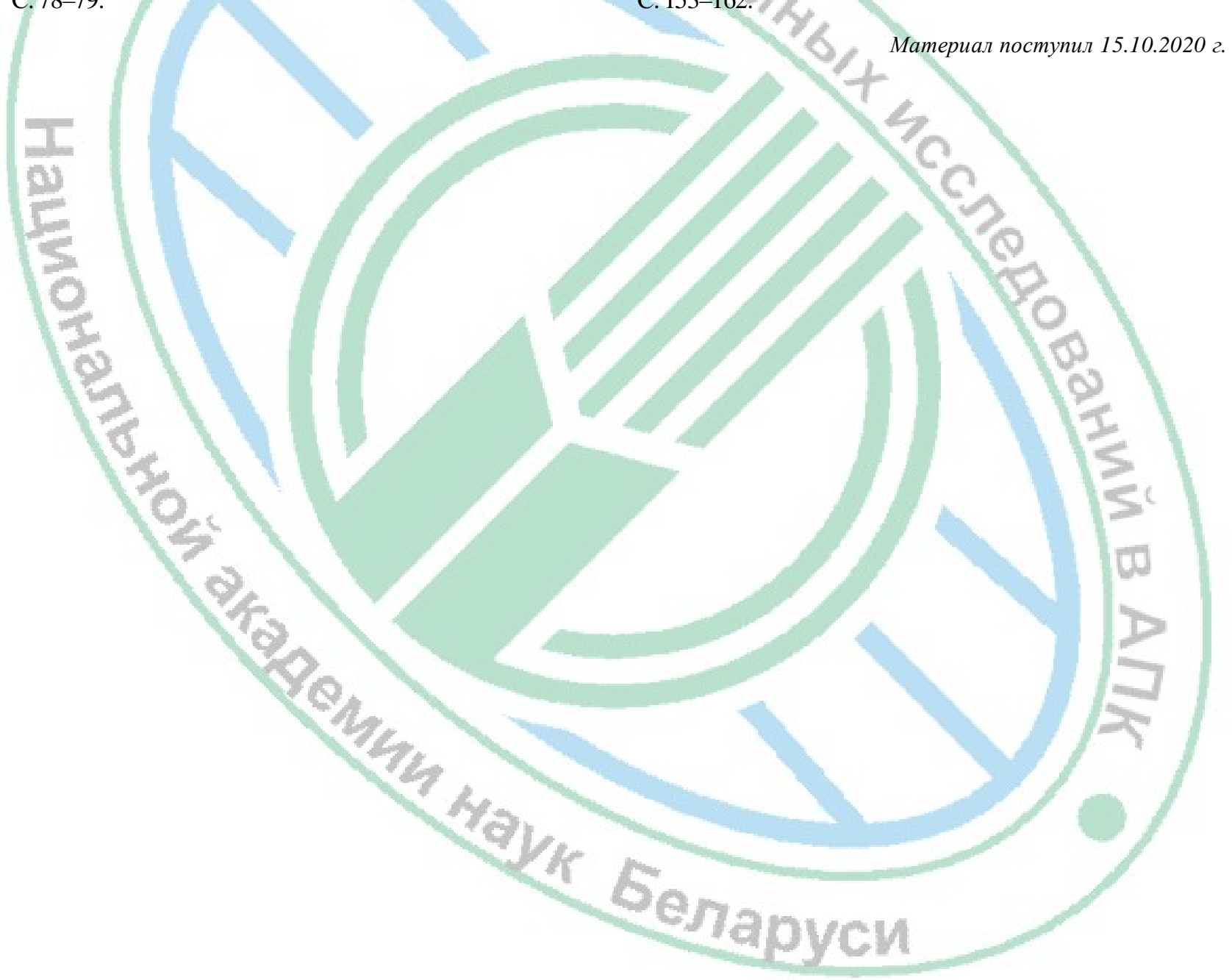

